\title{
Epidemiological Studies on Canine Mammary Tumour and its Relevance for Breast Cancer Studies
}

\author{
Kuldip Gupta ${ }^{1}$, Naresh Kumar Sood ${ }^{1}$, Sanjeev Kumar Uppal ${ }^{2}$, Jitender Mohindroo ${ }^{3}$, \\ Shashikant Mahajan ${ }^{3}$, M Raghunath ${ }^{3}$ and Kiranjeet Singh $^{3}$ \\ ${ }^{I}$ Department of Veterinary Pathology, 2.Department of Veterinary Medicine and 3.Department of Veterinary of Surgery and \\ Radiology, College of Veterinary Science, Guru Angad Dev Veterinary and Animal Sciences University, Ludhiana-141 004, \\ Punjab, India.
}

\begin{abstract}
Breast cancer is the most common cancer in women. Its incidence is rising globally and more so in the developing countries. There is a need to look for suitable animal model for biomedical research and pharmaceutical trails for this dreadly disease. In this pursuit, huge naturally occurring resource of canine mammary tumour may provide valid answer to impending questions in a shorter time frame. However, the epidemiology of canine mammary tumour (CMT) is poorly documented, especially in India. The present review deals with global and Indian scenario related to epidemiology of canine mammary tumour and its relevance as a model for human breast cancer.
\end{abstract}

Keywords: Animal model, Breast cancer, Canine mammary tumour, Epidemiology, Incidence

\section{INTRODUCTION}

Breast cancer is the most frequent malignant tumor in human females and morbidity and mortality due to it continue to increase, despite remarkable progress in the field of early diagnosis and adjuvant therapy (Raica et al 2009).

Mammary neoplasms in dogs are the second most common neoplasms after skin tumors (Rezia et al 2009). Nearly $41 \%$ to $53 \%$ of the mammary tumors that occur in the bitch are malignant (Misdorp 2002). Malignant mammary tumors often have a poor prognosis due to high rate of recurrence as well as metastasis, necessitating surgery and in some cases adjuvant chemotherapy. Pre-operative determination of tumor type and differentiation between malignant and benign tumors is of importance in judging patient's prognosis and in designing therapy (Simon et al 2009). Dogs develop spontaneous tumours and share a common environment with people and, therefore, may be exposed to the same carcinogens. In addition as in humans, advancing age, progesterone treatment, obesity in early life and diet increases the risk of mammary tumors in dogs. Therefore, dogs are considered as natural animal model of human breast cancer for testing new drugs and preventive modalities, prior to human clinical trials (Rezia et al 2009, Rivera and von Euler, 2011).

\section{GLOBAL BACKGROUND}

\subsection{Incidence of canine mammary tumours}

According to Bloom 1954 mammary tumours represent 25 to $30 \%$ of all the tumours recorded in dogs. Andersen (1965) reported that mammary tumours appeared in 38\% of the female beagles during the first 8 years of their life.As per Moulton et al (1970) the frequency of mammary neoplasms in both the sexes of dogs was $16 \%$ of all the tumours observed in dogs. The incidence of malignant mammary tumours in different series of excised mammary tumours ranged from 24 to 76 per cent of total number (Misdorp et al 1973). Mitchell et al (1974) observed that from a total of 6,754 tumours of different organs in dogs, $720(11 \%)$ were related to mammary glands. Nearly one half of all mammary tumours were mixed mammary, while adenocarcinomas accounted for $37 \%$ of all mammary tumours. Different scientists from time to time have described that approximately 50 per cent of canine mammary tumours were malignant in nature (Hamilton 1974, Gilbertson et al 1983, Moulton 1990 and Yager et al 1993). In a survey of more than 30,000 animals with spontaneous neoplasms, Moulton (1990) observed that the number of mammary tumours exceeded the number of skin and connective tissue tumours and accounted for 25 per cent of all tumours recorded. Cotran et al (1994) revealed that mammary tumours were the most frequent neoplasms in both dogs as well as women.Yamagami et al (1996) also reported mammary tumours to be the most commonly occurring neoplasms in dogs next only to the skin tumours. Cullen et al (2002) reported that as compared to human beings, dogs were affected 4 times more often by mammary gland cancer, 8 times more often by bone cancer and twice more often by leukemia. Egenvall et al (2005) studied the incidence of mammary tumours in female dogs aged between 3 to 10 years and in different breeds of dogs in Sweden from 1995 to 2002. The overall incidence of mammary tumours was found to be 111 dogs per 10,000 dogs. The incidence of these tumours increased with age and varied with breed, from 319 
dogs per 10,000 dogs in the English springer spaniel to 5 dogs per 10,000 dogs in the rough-haired collie. The mortality rate due to mammary tumours was 6 deaths per 10,000 dogs, and it increased with age. In their study on 17053 dogs affected with different mammary gland lesions, Zatloukal et al (2005) reported high incidence of mammary glands tumours. Gupta (2008) in her studies on canine mammary tumours recorded an incidence of $25.85 \%$ of these tumours.

\subsection{Incidence of CMT according to age}

Bostock (1986) reported a marked increase in incidence of mammary tumours in dogs with increasing age, with a peak at about 11 years, followed by a slight decline thereafter. Boldizsar et al (1992) found highest incidence of canine mammary tumours at 10 years and it kept on increasing till 14 years of age. Sandhu (1995) observed highest incidence of mammary tumours in dogs aged between 6-10 years and lowest incidence between 0-4 years of age. Simon et al 1996 recorded $63.2 \%$ incidence of the mammary tumours in dogs aged between 8-12 years. Gill (1997) observed mammary tumours in canines in the age group varying from 2-14 years, highest frequency (27.27\%) was noted in the age group of 8-12 years followed by 6-8 years (24.24\%) and 10-12 years (12.21\%) and the lowest frequency was noted in the age group of 0-2 years, 2-4 years and $12-14$ years (3.03\% each). On the basis of his studies on canine mammary tumours, (Palta 2000) reported highest incidence in the age group of 10-12 years $(25.30 \%)$, followed by 6-8 years $(24.13 \%)$ and $8-10$ years $(21.26 \%)$ whereas the lowest incidence (2.30\%) in the age group of 0-2 years. Nayyar (2002) reported mammary tumours in dogs between 2-15 years of age, with an average of 9.6 years. Highest incidence was observed in animals aged 8-10 years (22.22\%) followed by 12-14 years (19.44\%), whereas, lowest incidence was recorded in the age group of 2-4 years (2.78\%) and no case of mammary tumours was recorded in the age group of 0-2 years. Sharma (2003) and Bala (2005) reported that the average age of occurrence of mammary tumours in dogs was 8 years and 9.1 years respectively. They observed highest incidence in age group of 8-10 years followed by 10-12 years whereas the lowest incidence in age group of 2-4 years. No case of mammary tumours was observed in animlas less than 2 year of age. Jain (2006) reported highest incidence of canine mammary tumours in the age group of $8-10$ years $(30.00 \%)$ followed by $10-12$ years $(22.50 \%)$, 4-6 years $(17.50 \%)$ and 6-8 years $(12.50 \%)$ whereas, the lowest incidence $(2.50 \%)$ was observed in dogs less than 2 years of age. Shivani (2007) observed mammary tumours in dogs aged between 1 to 15 years with an average of 8.8 years. The maximum number of cases were recorded in age group of 8-10 years (28.6\%) and least incidence was found below age of 4 years (3.57\%). No occurrence of affection was reported above 15 years of age. It was also observed that benign neoplastic lesions occurred at an earlier age (mean age 6.3 years) than malignant ones (mean age 9.7 years). Similarly Gupta (2008) reported that the age of dogs suffering from mammary tumours ranged from 2-16 years with a median age of 10.8 (2.5-16) years. The highest frequency (37.5\%) was recorded in 10-12 years of age and no case of these tumours was recorded in animals below 2 years of age.

\subsection{Incidence of CMT according to breed}

Fiedler (1975) reported highest incidence of mammary tumours in spaniel bitches (12.7\%) and lowest in mongrel (5.7\%). An incidence of mammary tumours of $42 \%$ in Dachshund, 15\% in Poodles, 10.8\% in Spaniels and 10\% in German Shepherds and other breeds have been reported by Knoll and Unger (1983). Owen (1991) observed that Dachshunds and Cocker Spaniels bitches had an increased risk of developing mammary tumours, while Chihuahuas had reduced risk. Beagles had a risk slightly higher than mean risk for all dog breeds. Boldizsar (1992) found Pulis (Hungarian breed) was the most predisposable breed to mammary tumour. Stone (1994) elucidated that dogs of sporting breeds like Pointer, Retriever, English setter, Spaniel, Poodle, Boston Terrier and Dachshunds had higher incidence of canine mammary tumours. Both Sandhu (1995) and Gill (1997) observed the high incidence of canine mammary tumours in Spitz breeds followed by Doberman Pinchers. Goldschmidt (1998) reported that small breeds of dog such as immature poodle, Yorkshire terrier, Chihuahua and Maltese white had high incidence of benign mammary tumours, while English Setter, Chihuahua, Miniature poodle and Afghan hound had high incidence of malignant mammary, whereas Golden retriever, Rottweiler and Boxer had minimal risk of developing mammary tumours. Atalay and Aydin 2001 observed that mammary tumours occurred in poodles, Caniche, Terriers, German Shepherds, Pinschers, mixed breeds and unknown breeds of dogs and malignant mammary tumours occurred more frequently in Poodle and Caniche breeds as compared to other breeds of dogs. Palta (2000) reported that Samoyed/white spitz breed most commonly suffered from canine mammary tumours $(34.10 \%)$ followed by Doberman (19.65\%) German Shepherd (9.83\%) non-descript (8.10\%), Labrador Retriever (7.57\%) Pointer (5.78\%) Crossbred (5.20\%), Dachshund (2.89\%), Boxer (2.31\%), Cocker Spaniel (1.73\%), Lhasa Apso (1.16\%) and Tibetian Mastif, Poodle and Irish Setter breeds (0.58\% each). Similarly Nayyar (2002) recorded highest incidence of mammary tumours in Samoyed/white spitz breed (33.33\%) followed by Doberman (22.22\%), Non-descript (11.11\%), Crossbred (8.33\%), Gaddi and Pointer (5.55\%) and Great Dane, German Shepherd, Labrador Retriever, Bull Terrier and cocker Spaniel (2.78\% each). Bala (2005) also observed that Samoyed/white spitz breed (38.46\%) was more prone to mammary tumours, followed by Labrador Retriever (23.07\%), German Shepherd (19.23\%), Doberman (7.69\%), Non-descript (7.69\%) and Dalmatian (3.85\%). Similarly highest incidence of canine mammary tumours in Samoyed/white spitz (35.05\%) followed by Doberman (15.00\%), 
German Shepherd (12.50\%), Non-descript (12.50\%), Labrador (10.0\%) and Gaddi, Pointer, Irish Setter and Lhasa apso (2.5\% each) has been reported (Jain 2006). Shivani (2007) revealed that Pomerian breed (36.36\%) most commonly suffered from mammary tumours,followed by German Shepherd (24.24\%), Labrador retriever (12.12\%), Spitz (9.09\%) and Dachshund (6.06\%). Breeds at minimal risk included Doberman, Apso, Golden Retriver and Non descript types (3.03 \%). Whereas, Gupta (2008) recorded maximum cases of canine mammary tumours in Samoyed/Spitz breed (57.5\%) followed by non-descript breed (15\%).

\subsection{AUTHORS' OBSERVATIONS - INDIAN SCENARIO}

\subsection{Overall incidence of CMT from biopsy records}

The incidence of CMT was calculated on the basis of biopsy samples of canine submitted to Histopathology and Immunopathology laboratory of the Department of Veterinary Pathology, Guru Angad Dev Veterinary and Animal Sciences University, Ludhiana from December 2008 to April 2010. During this period a total of 169 canine biopsy samples were submitted. On the basis of histopathology, 109 samples were found to be neoplastic and 60 samples were non-neoplastic. Out of 109 neoplastic biopsy samples, 51 were CMT and 58 were other tumours. Incidence of CMT in present study on the basis of biopsy samples was found to be $46.79 \%$ of the total canine tumours reported during this period (Fig. 1).Variable incidence of CMT has been reported by earlier workers from various parts of the world. A low incidence of CMT of $0.7 \%$ from Hungary (Boldizsar 1992), 8\% from India (Singh et al 1998), 14\% (Mulligan, 1975) from U.S. and 15.27\% from Germany (Kessler et al 1997) has been reported.

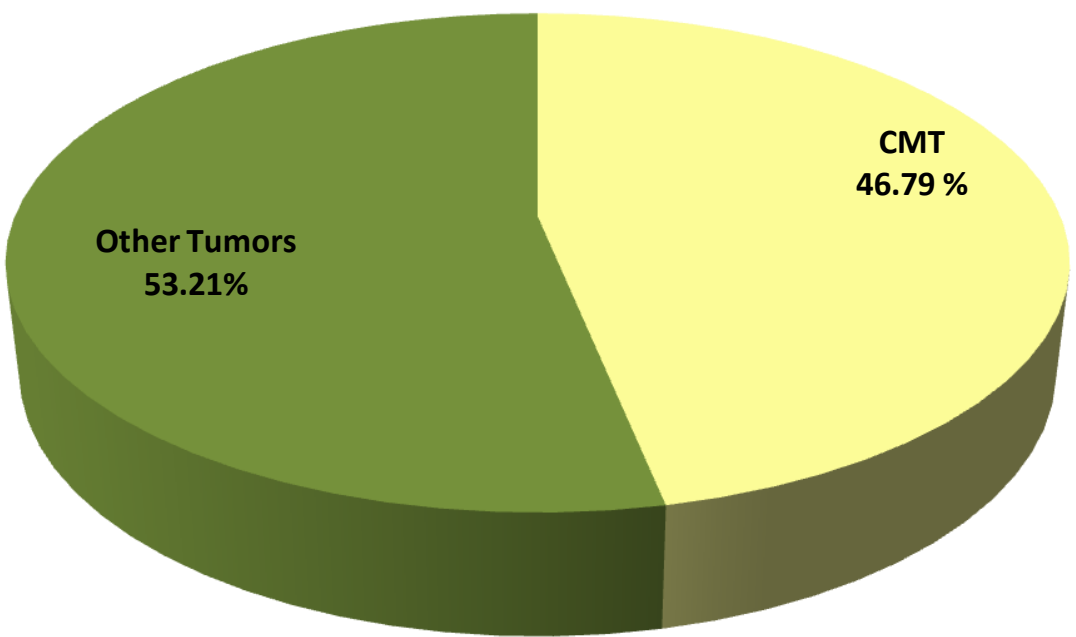

Fig. 1: Incidence of CMT amongst the total canine tumours

A moderate incidence of 24.32\% (Srivastava et al 2009), 26.73\% (Sandhu, 1995), 27.7\% (Gill, 1997), 28.9\% (Palta, 2000), $29.37 \%$ (Bala, 2005), $32.24 \%$ (Nayyar, 2002), 32.32 \% (Sharma, 2003) and 37.03\% (Jain, 2006), whereas, a higher incidence of CMT up to 51\% by Escudero et al (1982) has been reported. Benjamin et al 1999 and Pawar, 2006 concluded that canine mammary tumours accounted for half of all the tumours in bitches and approximately $40-50 \%$ of those were malignant. Perez Alenza et al (2000) reported that mammary tumours were the most frequent neoplasms in the bitch and their incidence was extremely high in those areas where early ovariectomy of bitches (before two years of age) was not practiced. This might be the reason for high incidence of CMT in the present study as early ovariectomy is not practiced by because female dogs are mostly reared for breeding purpose in this part of the world.

\subsection{Age-wise incidence of CMT}

Age-wise distribution of CMT is depicted in Fig. 2. The age of dogs affected with CMT varied from 2-16 years with a mean and median age of 8.8 and 9.0 years. Highest incidence of CMT was recorded in the age group of 10-12 years $(31.37 \%)$ followed by $8-10$ years $(23.53 \%)$ and 6-8 years $(15.69 \%)$ respectively, whereas, the lowest incidence $(1.96 \%)$ was observed in 14-16 and 16-18 years group and no case of CMT was reported in dogs less than 2 years of age. The results of age related distribution of CMT of the present study are consistent various earlier studies (Schneider 1970, Fowler et al . 1974, Mitchell et al . 1974, Pawar 2006, Shivani 2007 Gupta 2008 and Sassi et al 2010). Zatloukal et al 2005 also corroborated that tumours 
of the mammary gland occurred rarely in female dogs younger than 2 years of age and their incidence increased after the 5 years of age with a peak at the age of 10- 12 years followed by subsequent decrease (Moulton 1978).

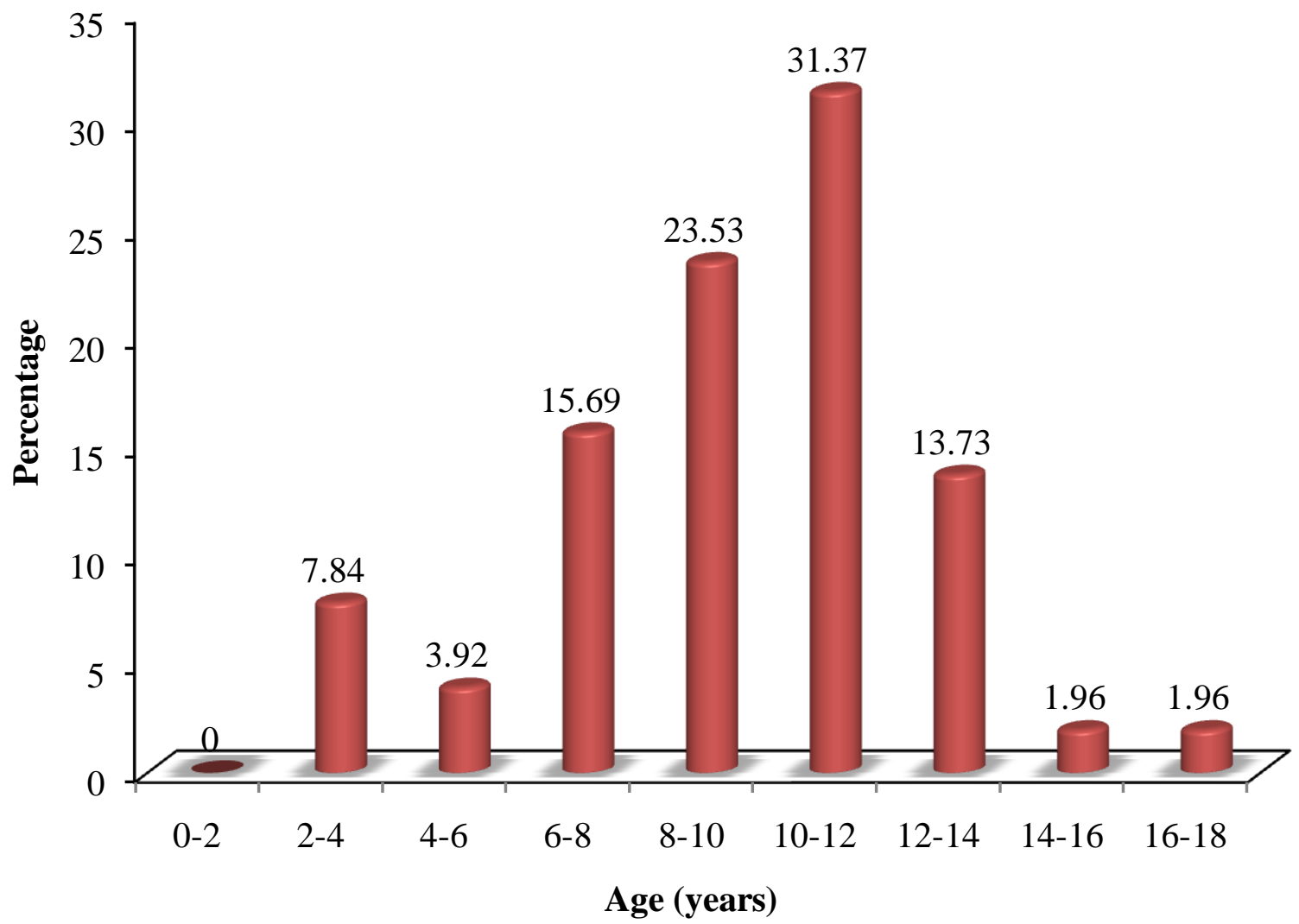

Fig. 2: Incidence of CMT according to age in years

\subsection{Incidence of CMT as per sex}

In the present study out of the 51 cases, only one case of mammary gland tumour was observed in a male dog and rest were all in the females. A variable incidence of mammary tumour in males from as high as 13.88 per cent (Ravi Kumar et al 1999) to as low as 1.7 per cent (Mitchell et al 1974) has been reported and its occurrence in male dogs is probably related to hormonal disturbances (Moulton 1990). In previous studies, Palta (2000) and Bala (2005), also reported mammary tumour in one male dog. In fact, CMT are specific tumours of females and are rare in males and are often associated with hormonal abnormalities (Moulton et al 1970).

\subsection{Breed -wise incidence of CMT}

Maximum incidence of CMT was observed in crossbred (19.61\%), followed by German shepherd (17.66\%), Labrador (13.73\%) and Spitz and dogs belonging to non- descript breed (11.76\% each). Dalmatian, Daschshund and Apso breeds had minimum incidence of CMT (Table). 
Table : Breed-wise incidence of CMT

\begin{tabular}{|l|l|l|l|}
\hline S. No. & Name of the Breed & Number of animals affected & Percentage \\
\hline 1. & Cross bred & 10 & 19.61 \\
\hline 2. & German shepherd & 9 & 17.66 \\
\hline 3. & Labrador & 7 & 13.73 \\
\hline 4. & Spitz & 6 & 11.76 \\
\hline 5. & Non-Descript & 6 & 11.76 \\
\hline 6. & Pomeranian & 3 & 5.88 \\
\hline 7. & Doberman & 3 & 5.88 \\
\hline 8. & Cocker Spaniel & 2 & 3.99 \\
\hline 8. & Gaddi & 2 & 3.92 \\
\hline 10. & Dalmatian & 1 & 1.96 \\
\hline 11. & Daschshund & 1 & 1.96 \\
\hline 12. & Apso & 1 & 1.96 \\
\hline
\end{tabular}

Variable breed-wise incidence of CMT has been described by earlier workers (Pawar 2006, Shivani 2007 and Gupta 2008). A considerably higher breed predisposition to mammary tumours has been reported in pure bred dogs compared to Mongrels (Dorn et al 1968, Zatloukal et al 2005). Hunting breeds namely Airedale Terrier, Brittany Spaniel, Boston Terrier, Cocker Spaniel, English Setter, English Springer Spaniel, Fox Terrier, German Shorthaired Pointer, Great Pyrenees, Irish Setter, Keeshond, Labrador Retriever, Pointer, Dachshund, Poodle and Samoyed have been reported to be predisposed to development of mammary tumours (Dorn et al 1968, Moulton et al 1970, Cohen et al 1974; Mitchell et al 1974, Mac Vean et al 1978 and Zatloukal et al 2005). Zatloukal et al 2005 further reported that pure-bred animals had higher risk of development of CMT. Moreover statistically significant breed predisposition to development of mammary gland tumours has been reported in Poodles, English Cocker Spaniels and Dachshunds (Cohen et al 1974, Mitchell et al 1974 and Zatloukal et al 2005).

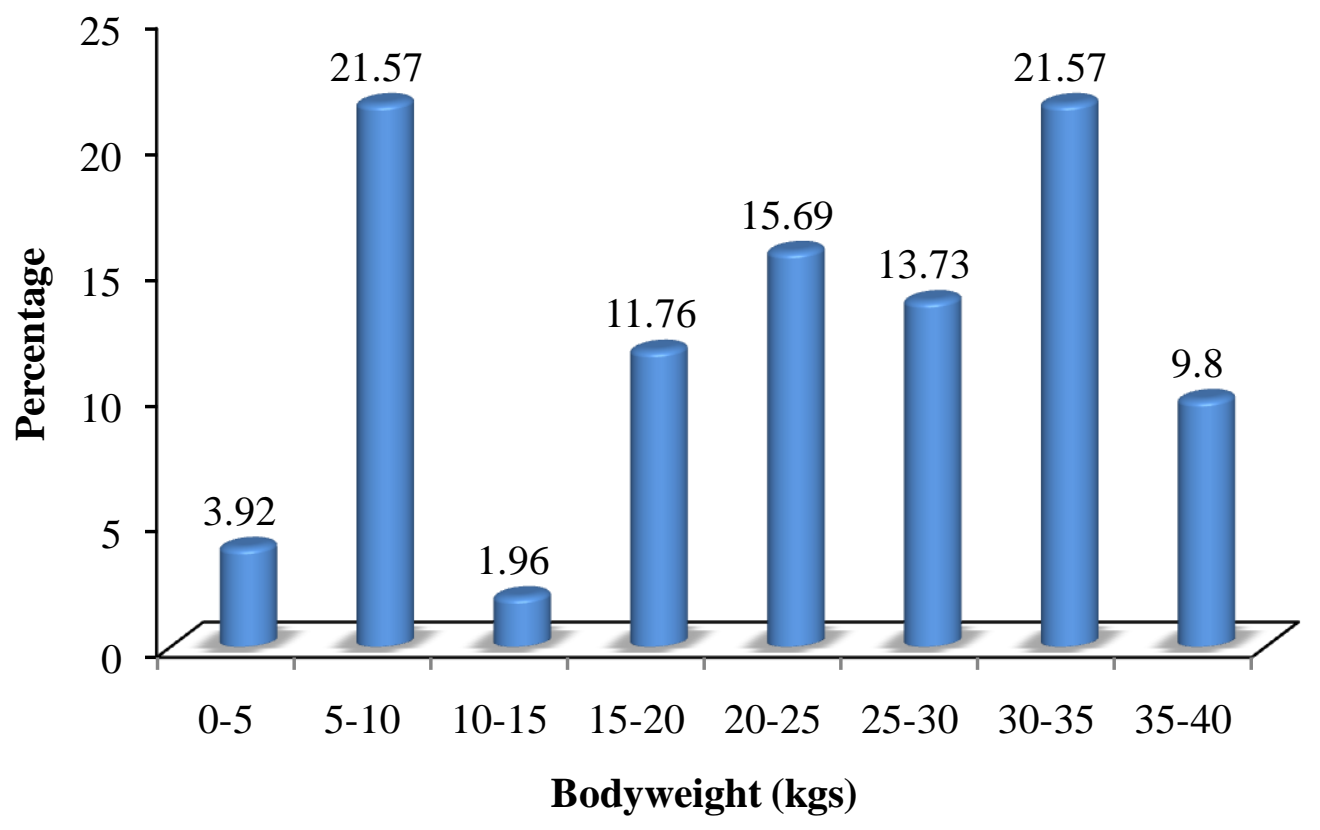

Fig. 3: Incidence of CMT according to body weight 


\subsection{Incidence of CMT according to bodyweight}

Maximum incidence (21.57\%) was observed in dogs having body weight between $5-10 \mathrm{Kg}$ and 30-35 $\mathrm{kg}$, followed by those having $20-25 \mathrm{Kg}, 25-30 \mathrm{~kg}$ and the minimum in dogs having body weight between $0-5 \mathrm{Kg}$ (3.92\%) (Fig. 3). These finding are similar to human being as obese females are at more risk of developing breast cancer (Cleary and Grossmann 2009) and the results of this study may be important since dogs are considered as natural animal model to study breast cancer.

\subsection{Incidence of CMT according to location}

Maximum involvement of fifth pair (56.86\%) of mammary glands followed by fourth pair (35.29\%), third, second pair (21.57 5\% each) and first pair (15.69\%) respectively were observed (Fig. 4). In most cases (45.10\%), only single or one pair of glands was involved, followed by two glands/pairs $(33.33 \%)$, three glands/pairs $(15.69 \%)$ and in $5.88 \%$ cases four glands/pairs were involved (Fig. 5).

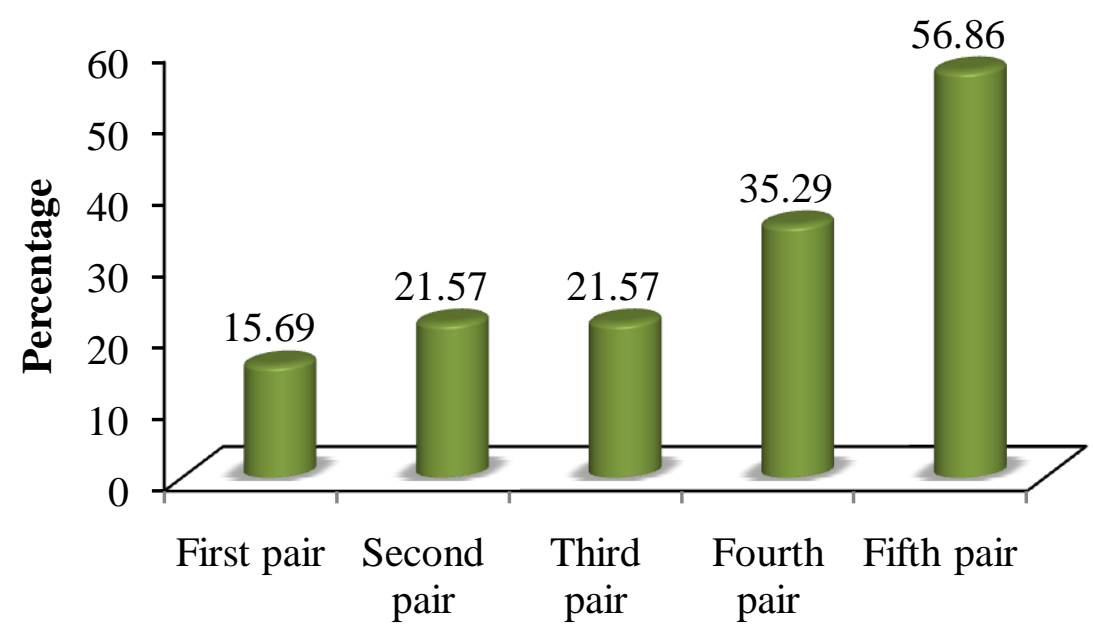

Location

Fig. 4: Incidence of CMT according to bodily location $(n=51)$

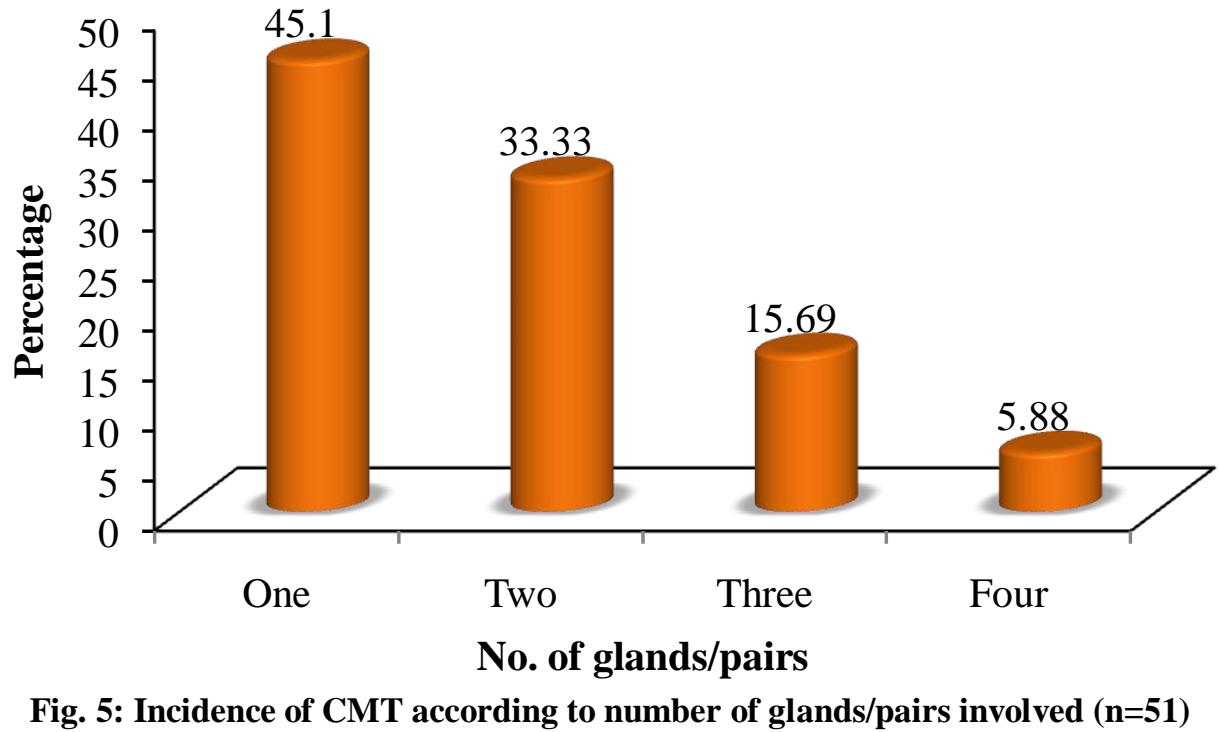

Fig. 5: Incidence of CMT according to number of glands/pairs involved $(n=51)$ 
The results obtained in the present study simulate earlier reports (Mulligan 1975, Sandhu 1995, Palta 2000, Nayyar 2002, Jain 2006, Shivani 2007 and Gupta 2008). Cohen et al 1974 and Ettinger and Feldman 1995 further concluded that approximately two third of CMT cases occurred in the fourth and fifth pair of mammary glands. Maximum involvement of the caudal glands may be due to the fact that they have maximum glandular tissue and they maintain their secretary activity longer than other pairs (Fidler et al 1967). Results pertaining to involvement of number of glands also matched with earlier reports of Sharma (2003), Bala (2005) and Jain (2006) who also found involvement of single gland or single pair of glands in majority of the cases of CMT. In contrast to the present findings, Gupta 2008 recorded greater involvement of two glands in CMT. Similarly, high incidence of multiple mammary involvement has also been reported by Fowler et al (1974), Mitchell et al (1974) and Mulligan (1975).

\subsection{RELEVANCE OF CANINE MAMMARY TUMOUR FOR HUMAN BREAST CANCER STUDIES}

Breast cancer in women is the second leading cause of cancer deaths not only in poor and developing countries but also in developed nations (Antuofermo et al 2007). It is becoming an increasingly global epidemic, plaguing more people in developing countries like India, where mortality rates are higher and many lack access to care. About 1.35 million cases of breast cancer were diagnosed worldwide in 2009, accounting for 10.5 percent of new cancers in second place behind lung cancer, according to the study by the Harvard School of Public Health. Breast cancer cases are expected to surge by 26 percent by 2020 with some 1.7 million new cases most of which will be in low- and middle-income developing countries. That is why the likelihood of dying from breast cancer, which is highly treatable if caught early on, hits a high of 56 percent in the poorest countries, 39 percent in middle income countries and only 24 percent in the wealthiest countries. However it has not received the requisite attention and funding as only five percent of the global resources for cancer are spent in the developing world. Breast cancer over the last two decades has attracted worldwide attention due to high mortality rates and its heterogeneity. Clinical and molecular similarities between canine mammary tumours and human breast cancer have been described in recent decades. Clinically, the similarities are very strong: spontaneous tumours, hormonal aetiology, age of onset and an identical course of the disease. The clinical characteristics that have an impact on the clinical outcome are also identical: tumour size, lymph node invasiveness and clinical stage. The magnanimity of the problem can be gauzed by the fact that scientists from across the globe and multifarious disciplines including pathologists, medical and surgical oncologists, biochemists, genetists, molecular biologists and those from ancillary biomedical fields and basic sciences have been collaborating to understand the disease and find its early remedial measures. Several of the research publications emerging recently are of multi-disciplinary and multi- nation origin ( Goncalves et al 2008, Parker et al 2009, de Ronde et al 2010). Currently the emphasis is also on dog as a naturally available spontaneous animal model of breast cancer as it shares the same environment, similar risk factors and molecular genetics. Moreover, recent findings of striking similarities between canine and human genome, oncogenic determinants of metastatic mammary tumours as well as canine, gene expression profile and human proteome, further validate the use of canine as model of human breast cancer. Nowadays, as far as human medicine is concerned, the goal is to identify prognostic factors, mainly at the molecular level, such as those involved in metastasis, which could be used as therapeutic targets to support a better outcome. For validating any animal model of human disease or cancer following considerations have to be critically evaluated in pharmaceutical industry and canine mammary tumour may provide a suitable on the basis of following criterias.

\subsection{The Ethical Considerations}

Medical research involving human subjects must conform to generally accepted scientific principles, be based on a thorough knowledge of the scientific literature, other relevant sources of information, and on adequate laboratory and, where appropriate, animal experimentation. An important principle, which implicitly guides the ethical evaluation of research projects is the use of the lowest number of animals belonging to the lowest phylogenetic position. In order to regulate the welfare of research animals during experimentation, following considerations are generally made i.e. promotion of nonanimal research methods, obtaining more information from the same number of animals and the use of methods, which alleviate or minimize potential pain, suffering, and distress to research animals. As dogs suffer spontaneously and highly frequently from mammary gland neoplasia, therefore, they fit very well into above ethical considerations as compared to rat and mice, because of need to induce mammary neoplasms in them experimentally. Moreover, the latest treatments discovered and apllied shall alleviate the dog mammary tumor, before its extrapolation to human mammary tumors. ( Porrello et al 2004). 


\subsection{The Clinical Considerations}

Cancer is one of the leading causes of death in both man and dog. Dogs, however, develop tumors approximately twice as frequently as their human counterparts. Studies have found that $45 \%$ of dogs that live to be 10 years or older die of cancer (Hahn et al., 1994). Mammary cancer is the most common neoplasm in the female dog, representing 52\% of all neoplasms ( MacEwen, 1990). Benjamin et al (1999) also observed that $70.8 \%$ of the female beagles had at least one mammary neoplasm and a few males were also found to have them. This study also found a significant association among related animals in the estimation of possible carcinoma. Some families of dogs are also predisposed to an early onset of cancer. Prevalence also varied by breed, with the Chihuahua having the lowest incidence (Benjamin et al 1999). Some breeds have shown to have increased risk of breast cancer; these include the smaller types of poodles, several types of spaniels, German Shepherds, Yorkshire Terriers, and Dachshunds (Sorenmo, 2003). Dogs are useful in cancer prevention studies, while the study is done in canines, it may also be applied to fight human breast cancer. Other non-human mammals have often been used for studying human cancer; full clinical tumors are studied in mice using human cancer cells, which can be injected and then grown in vivo. But for studying cancer development and progression, spontaneous cancer in dogs is a better model than the induced cancers in other laboratory animals. Prostate, bladder, and bone cancer in canines are very similar to their human counterparts (Knapp and Waters, 1997). Because pets are exposed to the same environmental factors, their cancers develop in much more similar pattern to humans. Dogs also have metabolism that better match that of humans, in contrast to laboratory rodents, making preliminary drug tests more meaningful (Knapp and Waters, 1997). The enrollment in clinical trials of dogs and, at the moment to a lesser extent, of cats with mammary cancer could compensate, at least partially, for the limitations of other experimental models. Indeed, cancer in pet dogs is a spontaneous event which is mostly age-related and/or induced by carcinogen exposure, typically in the urban settings. Remarkably, the age conversion scale adopted for pets allows the examination of tumor onset, progression and response to therapy in a well timed manner. (Albert et al 1994 and Patronek et al 1997), while in rodents the same phenomena happen in a compressed time scale, thus producing a Signal-to-Noise ratio unfavorable from a modeling point of view (Shiavi, 1999). The life span of companion animals, although condensed in comparison with men, still leaves enough time to study in detail toxicity, efficacy and eventual synergies of the administered treatments (Schneider 1970; Owen, 1979). Moreover, a number of studies is confirming that pet tumors are close to those of humans in terms both of incidence and outcome with a significant likeness of the genes involved in the process of tumor genesis (Veldhoen et al 1999; Matsuyama et al 2001 ). Pet tumors may help to elucidate several aspects of cancer biology in conditions that resemble those of human clinic, due to the possibility to perform intra -tumoral monitoring, sequential biopsies, molecular diagnosis, and imaging studies. (Nasir et al 2001). Furthermore, size and weight of pets are large enough to carry out, practically without other limitations than those of animal welfare, studies based on the latest techniques that are being transferred from basic research to clinical practice, e.g. genomics, transcriptomics, proteomics, which involve the multiple collection of sera, tissues, blood samples, etc At least a dozen histotypes of canine cancers including canie mammary tumor are hypothesized to be appropriate models for human neoplasms (Morrison ,1998; Patterson 1982 ; Knapp and Waters, 1997). A paradigmatic example of similarity between man and dog tumors, from a genetic, immunological, pathological, toxicological and hormonal standpoint, is also given by osteosarcoma . Other histotypes that are producing a valuable collection of data are canine vescical tumors, hemangiosarcomas, and prostate tumors. (Porrello et al 2004).

\section{3. The Financial Considerations}

In order to exemplify and compare the financial returns of medical research a study was made by a coalition of health care organizations, including pharmaceutical Research and Manufacturers of America, Advanced Medical Technology Association, American College of Cardiology, American Hospital Association, Federation of American Hospitals, Healthcare Leadership Council, and National Pharmaceutical Council. According to this study every dollar spent on medicines that lower diabetics' cholesterol produces $\$ 3.00$ in health gains; Every dollar spent on antiplatelet therapy for preventing strokes in high-risk patients provides health gains valued at $\$ 2.00$ to $\$ 6.00$; Each additional dollar spent on new hormonal therapies to treat breast cancer results in at least $\$ 27$ of health gains. In this context, the possibility to administer a therapy earlier to a larger heterogeneous population of model animals that may expose side-effects, prior to undertaking expensive Phase II and III trials on women, is potentially precious (Freireich 1997). Though the processes of carcinogenesis and tumor progression in pets are much more accelerated than in humans, nonetheless they leave enough time to study the clinical response to conventional and experimental therapeutics. Additionally, the enrolled companion animals mostly continue to live with their owners even during the trials and do not need to be housed in animal facilities, thus allowing to save significant amounts of money (Porrello et al 2004). 


\subsection{CONCLUSIONS}

Spontaneous mammary tumors in dogs are appropriate and valid model tumor systems available for study. Dogs develop spontaneous mammary tumors with clinical and biologic behavior similar to tumors that occur in humans. The pet population is a vastly underutilized for testing cancer therapeutic agents or studying cancer biology of mammary neoplasia. The futuristic goals of predictive and prognostic evaluation of breast cancer can better be achieved by using this vast natural resource as animal model at much lower expenses.

\section{REFERENCES}

1. Albert R E, Benjamin S A and Shukla R. 1994. Life span and cancer mortality in the beagle dog and humans. Mechanisms of Ageing and Development 74: 149-159.

2. Andersen A C. 1965. Parameters of mammary gland tumors in aging beagles. Journal of American Veterinary Medical Associattion 147: 1653- 54.

3. Antuofermo E. Miller M A. Pirino S. Xie, J. Badve S and Mohammed S I. 2007. Spontaneous Mammary Intraepithelial Lesions inDogs-A Model of Breast Cancer. Cancer Epidemiol Biomarkers Prev. 16:2247-56

4. Atalay V S and Ayadin Y. 2001. A survey of canine mammary tumors from 1973 to 1998 in Ankard. Turk Vet Hayvan Derg 25: 233-39 (Original not seen Abstr from CAB abstracts AN: 20013074800).

5. Bala M. 2005. 'Clinical studies on the evaluation of doxorubicin as an aduvant chemotherapy for the management of canine mammary neoplasms'. M.V.Sc. Thesis, Punjab Agricultural University, Ludhiana.

6. Benjamin S A, Lee A C and Saunders W J. 1999. Classification and behavior of canine mammary epithelial neoplasms based on life-span observations in beagles. Veterinary Pathology 36: 423-36.

7. Bloom F. 1954. Pathology of the dog and cat, the genitourinary system, with clinical considerations pp. 418-424. American Veterinary Publications, Evanston, Illinois.

8. Boldizsar H, Szenci O, Muray T and Senki J. 1992. Studies on canine mammary tumors. I. Age, seasonal and breed distribution. Acta Veterinaria Hungarica 40: 75-87.

9. $\quad$ Bostock D E. 1986. Canine and feline mammary neoplasms. British Veterinary Journal 142: 506-15.

10. Cleary M P and Grossmann M E. 2009. Obesity and Breast Cancer: The Estrogen Connection Endocrinology 150: 2537-42.

11. Cohen D, Reif J S, Brodey R S and Keiser H. 1974. Epidemiological analysis of the most prevalent sites and types of canine neoplasia observed in a veterinary hospital. Cancer Research 34: 2859- 68.

12. Cotran R S, Kumar V, Robbins S L and Schoen F J. 1994. The Breast. In: Cotran R S, Kumar V, Robbins S L and Schoen F J (ed) Pathologic Basis of Disease (5th edn), pp 1089-1111. WB Saunders, Phildelphia, PA.

13. Cullen J M, Page R and Misdorp W. 2002. An overview of cancer pathogenesis, diagnosis and management. In : Moulton D J (ed) Tumors in Domestic Animals, pp 3-45. Blackwell Publishing Company, Iowa State Press, U.S.A

14. de Ronde J J, Hannemann J, Halfwerk H, Mulder L, Straver M E, Marie-Jeanne T F D, Peeters V, Wesseling J, van de Vijver M, Wessels L F A and Rodenhuis S.2010. Concordance of clinical and molecular breast cancer subtyping in the context of preoperative chemotherapy response. Breast Cancer Res Treat 119:119-126 DOI 10.1007/s10549-009-0499-6.

15. Dorn C R, Taylor D O, Schneider R, Hibbard H H and Klauber M R. 1968. Survey of animal neoplasms in Albeda and Contra Costa counties, California. II. Cancer morbidity in dogs and cats from Almeda county. Journal of the National Cancer Institute 40: 307-18.

16. Egenvall A, Bonnett B N, Ohagen P, Olson P, Hedhammar A and von Euler H. 2005. Incidence of and survival after mammary tumors in a population of over 80,000 insured female dogs in Sweden from 1995 to 2002. Preventive Veterinary Medicine 69: 109-27.

17. Escudero A, Martinez J M, Espinosa J and Sanchoz A. 1982. Analysis of 372 neoplasms of domestic animals. Anal Fac Vet Leon 28: 29-37 (Original not seen Abstr. From Vet C D CDROM AN: 842233856).

18. Ettinger S J and Feldman E C. 1995. Textbook of Veterinary Internal Medicine Vol. 2 pp 1702-04. W. B. Saunders and Co., Philadelphia.

19. Fiedler H. 1975. Frequency of tumors in dogs with special reference to skin and mammary tumors. Inaugural Dissertation, Fachbereich Tiermedizin Munchen : 140 (Original not seen. Abstract in Veterinary Bulletin, 47: Entry No 4527).

20. Fidler I J, Abt D A and Brodey R S. 1967. The biological behavior of canine mammary neoplasms. Journal of American Veterinary Medical Association 151: 1311-16. 
21. Fowler E H, Wilson G P and Koestner A. 1974. Biologic behavior of canine mammary neoplasms based on a histological classification. Veterinary Pathology 11: 212-29.

22. Freireich E J. 1997. Societal issues in oncology: Regulatory issues. In: De Vita VT. Hellman S. Rosenberg S A. (eds). Cancer: principles and practice of oncology. $5^{\text {th }}$ Edition. Philadelphia,PA, Lippincott, pp 29662972.

23. Gilbertson S R, Kurzman I D, Zachrcur R E, Hurvitz A I and Black M M. 1983. Canine mammary epithelial neoplasms: Biologic implications of morphologic characteristics assessed in 232 dogs. Veterinary Pathology 20: 127-42.

24. Gill K S.1997. 'Clinical studies on canine mammary tumours with reference to its surgical and chemotherapeutic management'. M. V. Sc Thesis, Punjab Agricultural University, Ludhiana.

25. Goldschmidt M H.1998. Breed related cancers. The $28^{\text {th }}$ Annual Canine Symposium, University of Pennsylvania.

26. Goncalves A, Charafe-Jauffret E , Bertucci F, Audebert S, Toiron Y, Esterni B, Monville F, Tarpin C, Jacquemier J, Houvenaeghel G, Chabannon C, Extra J M, Viens P, Borg J P , and Birnbaum D .2008. Protein Profiling of Human Breast Tumor Cells Identifies Novel Biomarkers Associated with Molecular Subtypes. Molecular \& Cellular Proteomics 7:1420-1433

27. Gupta P. 2008. 'Diagnosis of canine mammary neoplasms and their management with adjuvant chemotherapy using vincristicine, methotrexate and cyclophosphamide'. M.V.Sc. Thesis, Guru Angad Dev Veterinary and Animal Sciences University, Ludhiana.

28. Hamilton J M. 1974. Comparative aspects of mammary tumors. Advanced Cancer Research 19: 13-26.

29. Hahn K.A, DeNicola D.B, Richardson R.C, Hahn E.A (1994). Canine oral malignant melanoma: Prognostic utility of an alternative staging system. Journal of Small Animal Practice 35: 251-256.

30. Jain V. 2006. 'Studies on management of canine mammary neoplasms by adjuvant chemotherapy using combination of doxorubicin and cyclophosphamide'. M.V.Sc. Thesis, Guru Angad Dev Veterinary and Animal Sciences University, Ludhiana.

31. Kessler M, Bomhard D von and Von-Bomhard D.1997. Paediatric tumors in small animals. Berliner-undMunchener-Tierarztilche-Wochenschrift 110: 311-14.

32. Knapp D W and Waters D J. 1997. Naturally occurring cancer in pet dogs: important models for developing improved cancer therapy for humans. Molecular Medicine Today 3: 8-11

33. Knoll L and Unger H.1983. Surgical mammary tumors of the bitch. Prakhsche-Tierarzt 64: 451-54 (Original not seen. Abstract in VETCD. CDROM. AN : 832230791).

34. MacEwen E G. 1990. Spontaneous tumors in dogs and cats: Models for the study of cancer biology and treatment. Cancer and Metastasis Reviews 9:125-136.

35. Mac Vean D W, Monlux A W, Anderson P S, Silberg S L and Roszel J F.1978. Frequency of canine and feline tumors in a defined population. Veterinary Pathology 15: 700-15

36. Matsuyama S, Nakamura M , Yonezawa K, Shimada T, Ohashi F , Takamori Y and Kubo K. 2001. Expression patterns of the erbB subfamily mRNA in canine benign and malignant mammary tumors. Journal of Veterinary Medical Science 63: 949-954.

37. Misdorp W. 2002. Tumors of the mammary gland. In: Meuten D J (ed) Tumors in Domestic Animals. pp 575-606. Iowa State Press, Ames, Iowa

38. Misdorp W, Cotchin E, Hampe J F, Jabara A G and Sanderson J V. 1973. Canine malignant mammary tumors. III. Special types of carcinomas, malignant mixed tumors. Veterinary Pathology 10: 241-56.

39. Mitchell L, De La Iglesia F A, Wenkoff M S, Van Dreumel A A and Lumb G. 1974. Mammary tumors in dogs: Survey of clinical and pathological characteristics. Canadian Veterinary Journal 15: 131-38.

40. Morrison W B. 1998 . Cancer in dogs and cats: medical \& surgical management. $2^{\text {nd }}$ Edition. Baltimore, ML, Williams \& Wilkins.

41. Moulton J E. 1978. Tumours of mammary gland. In: Moulton J E (ed) Tumours in Domestic Animals (2 ${ }^{\text {nd }}$ edn) pp 342-369. University of California Press, Berkeley and Los Angeles.

42. Moulton J E. 1990. Tumours of mammary gland. In: Moulton J E (ed) Tumours in Domestic Animals (3 ${ }^{\text {rd }}$ edn.) pp 518-52. University of California Press, Berkeley and Los Angeles.

43. Moulton J E, Taylor D O, Dorn C R and Andersen A C. 1970. Canine mammary tumors. Pathologia Veterinaria 7: 289-320.

44. Mulligan R M. 1975. Mammary cancer in the dog: A study of 120 cases. American Journal of Veterinary Research 36: 1391-96. 
45. Nayyar A. 2002. 'Evaluation of Vinblastine and Mitomycin in conjugation with surgery in canine mammary neoplasms'. M. V. Sc Thesis, Punjab Agricultural University, Ludhiana.

46. Nasir L, Devlin P, Mckevitt T, Rutteman G and Argyle D J. 2001. Telomere lenghts and telomerase activity in dog tissues: a potential model system to study human telomere and telomerase biology. Neoplasia 3: 351-359

47. Owen L.N. 1979. A comparative study of canine and human breast cancer. Invest. Cell Pathology 2: 257275.

48. Owen L N. 1991. Identifying and treating cancer in geriatric dogs. Veterinary Medicine 86: 55-66.

49. Palta M K. 2000. 'Clinical studies on multimodality in the management of canine mammary neoplasm'. M.V.Sc. Thesis, Punjab Agricultural University, Ludhiana.

50. Parker J S, Mullins M, Cheang M C.U., Leung S, Voduc D, Vickery T, Davies S, Fauron C, He X, Hu Z , Quackenbush J F, Stijleman I J, Palazzo J, Marron J S , Nobel A B , Mardis E, Nielsen T O, Ellis M J., Perou C M , and Bernard P S. 2009. Supervised Risk Predictor of Breast Cancer Based on Intrinsic Subtypes. J Clin Oncol 27:1160-1167

51. Patronek G J, Waters D J and Glickman L T. 1997. Comparative longevity of pet dogs and humans: implications for gerontology research. Journals of Gerontology Series A: Biological Sciences and Medical Sciences 52: 171- 178.

52. Patterson D F, Haskins M E and Jezyk P F. 1982 . Models of human genetic disease in domestic animals. Advances in Human Genetics 12: 263-339

53. Pawar S K. 2006. 'Epidemiological studies of canine neoplasms with special reference to mutational analysis of p53 gene in canine mammary tumors by PCR-SSCP'. M.V.Sc. Thesis, College of Veterinary Science and Animal Husbandry Anand, Agricultural University, Anand.

54. Perez Alenza M D, Pena L, Castillo N D and Nieto A I. 2000. Factors Influencing the Incidence and Prognosis of Canine Mammary Tumours. Journal of Small Animal Practice 41: 287-291.

55. Porrello A. Cardelli P. and Spugnini E. P (2004). Pet Models in Cancer Research: General Principles. Journal of Experimental and Clinical Cancer Research 23: 181-193.

56. Raica M, Jung I, Cimpean A M, Suciu C and Muresan A M. 2009. From conventional pathologicdagnosis to the molecular classification of breast carcinoma: Are we ready for the change? Romnian Journal of Morphology and Embryology 50: 5-13.

57. Ravi Kumar K P, Vasanth M S, Ranganath B N and Jayadevappa S M. 1999. Incidence of mammary tumour in canines. Indian Journal of Veterinary Surgery 20: 115.

58. Rezia A, Tavasoli A, Bahonar A and Mehrazma M. 2009. Grading in canine mammary gland carcinoma. Journal of Biological Sciences 9: 333-38.

59. Rivera P and von Euler H. 2011. Molecular biological aspects on canine and human mammary tumors. Veterinary Pathology 48: 132- 46.

60. Sandhu N S. 1995. 'Studies on the surgical and chemotherapy management of canine mammary neoplasms'. M.V.Sc. thesis, Punjab Agricultural University, Ludhiana, India

61. Sassi F, Benazzi C, Castellani G and Sarli, G. 2010. Molecular-based tumor subtypes of canine mammary carcinomas assessed by immunohistochemistry. B M C Veterinary Research 6:5-13.

62. Schneider R. 1970. Comparison of age, sex and incidence rates in human and canine breast cancer. Cancer 26: 419-26.

63. Sharma H K. 2003 'Studies on presurgical use of mitomycin and vinblastine in canine mammary neoplasms'. M.V. Sc. Thesis, Punjab Agricultural University, Ludhiana.

64. Shiavi R. 1999. Introduction to applied statistical signal analysis. 2nd Edition, San Diego, CA, Academic press.

65. Shivani. 2007. 'Cytopathology of canine mammary gland affections with special reference to mammary gland tumors'. M. V. Sc Thesis, GADVASU, Ludhiana, India.

66. Simon D, Goronzy P, Stephan I, Meyer-Lindenberg A, Aufderheide M and Nolte L.1996. Mammary tumors in the dog: frequency and course. Practische-Tierarzt 771-82 (Original not seen. Abstract in Veterinary Bulletin 66: Entry No. 8148).

67. Simon D, Schoenrock D, Nolte I, Baumgartner W, Barron R and Mischke R. 2009. Cytologic examination of fine- needle aspirates from mammary gland tumors in the dog: diagnostic accuracy with comparasion to histopathology and association with postoperative outcome. Veterinary Clinical Pathology 38: 521-28.

68. Singh M, Nigam J M, Sharma S K, Varshney A C and Sharma A. 1998. Clinical studies on canine neoplasm: Review of small animal surgery cases. Indian Journal of Veterinary Surgery 19: 47. 
69. Sorenmo K. 2003. Canine mammary gland tumors. Veterinary Clinics of North America 33:573-596.

70. Srivastava A K, Sharma A K and Singh B. 2009. Canine mammary tumours: A study on occurrence and distribution pattern. Indian Journal of Veterinary Pathology 33: 109-11.

71. Stone E A. 1994. Mammary gland neoplasia. In : Birchard S J and Sherding R G (eds) Saunders Manual of Small Animal Practice pp 207-10. W B Suanders Co., Philadelphia

72. Veldhoen N, Watterson J, Brash M and Milner J. 1999. Identification of tumour-associated and germ line p53 mutations in canine mammary cancer. British Journal of Cancer 81: 409-415

73. Yager J A, Scott D W, Wilcock B P. 1993. The skin and appendages. In : Jubb KV F, Kennedy P C and Palmer N (eds) Pathology of Domestic Animals ( $4^{\text {th }}$ edn) pp 531-738. Academic Press, San Diego, C A.

74. Yamagami T, Kabayashi T, Takahashi K and Sugiyama M. 1996. Prognosis for canine malignant mammary Tumour based on TNM and histologic classification. Journal of Veterinary Medical Science 58: 1079-83.

75. Zatloukal L, Lorenzova J, Tichy F, Necas A Kecova H and Kohout P. 2005. Breed and age as risk factor for canine mammary tumors. Acta Veterinaria Brunensis 74 : 103-09. 